\title{
Development of a Thermal and Structural Analysis Procedure for Cooled Radial Turbines
}

Ganesh N. Kumar

Sverdrup Technology, Inc.

NASA Lewis Research Center Group

Cleveland, Ohio

and

Russell G. DeAnna

Propulsion Directorate

U.S. Army Aviation Research and Technology Activity-AVSCOM

Lewis Research Center

Cleveland, Ohio

Prepared for the

33rd International Gas Turbine and Aeroengine Congress and Exposition sponsored by the American Society of Mechanical Engineers

Amsterdam, The Netherlands, June 6-9, 1988

\section{N/Sh}

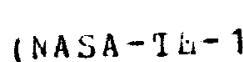

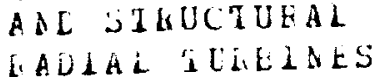

DEVELCENEAT (NASA)
$10 \mathrm{~F}$

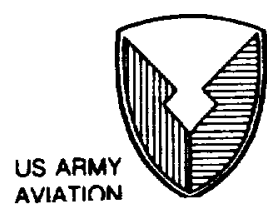

N 89-12508 



\section{Development of a Thermal and Structural Analysis Procedure for Cooled Radial Turbines}

GANESH N. KUMAR

Sverdrup Technology, Inc.

NASA Lewis Research Center Group

Cleveland, $\mathrm{OH} 44135$ and

\author{
RUSSELL G. DEANNA \\ Propulsion Directorate \\ U.S. Army Aviation Research and \\ Technology Activity-AVSCOM \\ NASA Lewis Research Center \\ Cleveland, $\mathrm{OH} 44135$
}

ABSRACT

A procedure for computing the rotor temperature and stress distributions in a cooled radial turbine is considered. Existing codes for modeling the external mainstream flow and the internal cooling flow are used to compute boundary conditions for the heat transfer and stress analyses. An inviscid, quasi three-dimensional code computes the external free stream velocity. The external velocity is then used in a boundary layer analysis to compute the external heat transfer coefficients. Coolant temperatures are computed by a viscous one-dimensional internal flow code for the momentum and energy equation. These boundary conditions are input to a threedimensional heat conduction code for calculation of rotor temperatures. The rotor stress distribution may be determined for the given thermal, pressure and centrifugal loading. The procedure is applied to a cooled radial turbine which will be tested at the NASA Lewis Research center. Representative results from this case are included.

\section{INTRODUCTION}

Increasing the turbine-inlet temperature is the most lucrative approach to improving thermal efficiency and specific thrust of gas turbines. However, this practice is 1 imited by the availability of materials which can withstand these high temperatures. Current materials cannot be exposed to temperatures above $1250 \mathrm{~K}$ without a dramatic decrease in life [1]. Blades must be cooled if significantly higher turbine inlet temperatures are desired. Mainstream air diverted from the compressor exit is used to cool the turbine. This reduces the thermal efficiency of the system. Therefore, minimizing the cooling air stream is an important task in gas turbine design. Cooled axial flow turbines have traditionally been used in these engines.

In small engines, the radial turbine has several inherent advantages over the axial turbine. Normally, the work extracted and efficiency level of two axial stages can be achieved by a single radial stage. This leads to a reduction in overall engine camplexity, length, and weight. These attributes have resulted in the widespread use of uncooled radial turbines in automotive turbochargers and auxiliary power units. The radial turbine has not been used as a primary power source - where high temperatures and pressures are desired - because of the difficulties associated with fabrication of the internal cooling passages. Most of these fabrication barriers have been resolved to the point where it is feasible to design an engine with a cooled radial turbine.

Several programs have looked at the fabrication and performanoe of small cooled radial turbines. The first major attempt at an internally cooled radial turbine rotor was initiated under the U.S. Anmy in $1968[2,3]$. The turbine was designed for a $2300 \mathrm{~F}$ turbine inlet temperature a $2300 \mathrm{ft} / \mathrm{sec}$ tip speed, a pressure ratio of $5: 1$, and a corrected specific work of 40 Btu $1 \mathrm{~lm}$. The design required $3 \frac{8}{8}$ of engine airflow for rotor blade cooling and achieved a total efficiency of 87.5\%. Although this design clearly displayed the radial turbines advantage, the fabrication of test hardware was met with problems. In 1977 the Army sponsored a radial turbine program with the objective of providing and demonstrating the technology required to econamically manufacture a cooled high temperature radial turbine $[4,5]$. One approach used photo etched laminates bonded together to form a camplete wheel. The other approach used a cast airfoil shell diffusion bonded to a powdered metal disk. Both programs showed pramising results An ing design of a cooled turbine is the knowledge of the temperature and stress distribution throughout the rotor. As prototype experiments are usually extremely expensive, there is a great need for theoretical prediction methods [1]. A calputational procedure has been developed by the authors to assist in the analysis and design of a cooled radial turbine. This procedure predicts the three-dimensional rotor temperature and stress distribution for a given set of operating conditions. The method 
uses a quasi three-dimensional inviscid code in conjunction with a boundary layer code to campute the external blade surface heat transfer coefficients. Coolant passage heat transfer coefficients and collant temperatures are computed by a viscous one-dimensional internal flow code. A three-dimensional heat conduction code uses these results to compute the rotor temperature distribution. A detailed stress analysis can also be requested.

To minimize the time and effort required for complete analysis, the entire procedure is automated. Once the procedure is started, it will go through each step of the procedure in the appropriate sequence, iterating between solutions until onvergence is achieved.

\section{ANALYSIS FROCEUURE}

Four main codes are linked into a procedure to compute the steady-state rotor temperature and stress distributions. The four codes are: MERIDL/TSONIC/STAN5, CPFRHA, SINDA and NASTRAN.

The three code set, MERIDL/TSONIC/STAN5, is used to compute the external heat transfer coefficients along streamlines on both the suction and pressure surfaces $[6,7,8]$. MERIDL is used to compute the mid-channel streamline positions fram hub to shroud. TSONIC uses each of these streamlines to determine the flow conditions on a surface between two blades. Stacking these surfaces from hub to shroud produces a quasi three-dimensional solution. MERIDL and TSONIC are steady'state, inviscid, two-dimensional codes applicable to a perfect gas.

The inviscid blade surface velocities from the MERIDL/TSONIC combination form the input to STAN5. These are used as external free stream velocities in the boundary layer analysis. STAN5 uses these velocities to compute a two-dimensional boundary layer along each streamline. The calculated heat transfer oofficients are used as boundary conditions in the conduction analysis. The free stream velocities must be "smoothed" if STAN5 predicts regions of separated flow.

CPFRHA (Coolant Passage Flow with Rotation and Heat Addition) is used for computing the internal coolant temperature, pressure and heat transfer coefficients along the coolant flow path [9]. It integrates the one-dimensional momentum and energy equations along a path. The equations account for area change, rotation, friction and heat addition. Flow splits cannot be determined with this code. The internal cooling passages that can be acoumodated in the procecture include plain passages, finned passages, trip strips, pin fins, tip cap impingement, etc. The coolant passage wall temperature distribution and colant inlet conditions are a required input. Thus, an iterative process between CPFRHA and the heat conduction code must be used since the wall temperature distribution is not known apriori.

The heat conduction code SINDA (Systems Improved Numerical Differencing Analyzer) [10] is used in the analysis procecture to perform detailed three-dimensional heat transfer analysis of the rotor. A wedge consisting of one blade and the corresponding disk region is analyzed.

Based on the converged temperature distribution in the rotor, the MERIDL/TSONIC external pressure distribution, and the CPFRHA internal coolant passage pressure distribution, a NASTRAN [11] structural analysis of the rotor is performed. From this analys is, nodal displacements, stress distribution and modal shapes of the rotor are obtained. The above procedure is based on the method developed by christie, et al, [12].

\section{MODEL GENERATION}

\section{NASTRAN Model}

Based on nodal points along the streamlines of the blade suction and pressure surfaces, the disk geanetry and the coolant passages geometry input data, a NASTRAN model of the blade and the associated disk is created by the code RITICN [13]. The data generated by this code can be used to:

1. Perform NASTRAN structural analysis on the blade and the disk.

2. Provide two of the six input files required by the code SMAIN4 [14]. The code SMAIN4 converts the NASTRAN model of RITICN to SINDA model for thermal analysis.

3. Provide plate and solid-element NASTRAN modeling, which when combined with RELACT temperature output provides input to the PATRAN 3-D color graphics plotting routines.

This preprocessing program generates the grid point and element connectivity data for a COSMIC/MSC NASTRAN finite element grid of a radial inflow turbine rotor with intermally cooled blades. The grid generated by this program consists of one blade and the associated sector of the rotor disk. The NASTRAN cyclic symmetry feature is employed for structural analysis, thus rendering the above as sufficient to model the entire rotor.

The basic turbine model generated employs a hollow blade which is modeled with triangular plate elements and a disk sector which is modeled with brick elements. Blade halves are attached to the disk using rigid elements. Along the blade tip, along the leading edge, and in the scallop region, the blade halves are tied together with quadrilateral plate elements. The exhaust end of the blade halves is open. The sides of the rotor hub are "tied" together (CYJODN) for utilization of the NASTRAN cyclic symetry feature. All of the above is automatically generated by the program. The user has great flexibility in generating a wide range of models due to the number of user specified input variables. A typical model is depicted in Figure 1 . The user may generate additional elements manually for the NASTRAN deck to model features which may be unique to a given concept/design (e.g. pins, baffles, ribs, etc. internal to the blade halves (skins)).

\section{SINDA Yodel}

The SINDA model consists of nodes and conductors which provide a lumped parameter representation of the turbine rotor and its themal boundary conditions. Nodes and conductors are generated along the streaml ines, nodal lines, and in the tangential direction following an order similar to that used in RITICN. Most nodes have three conductor numbers associated with their nodal number. One conductor is oriented in the streamline direction, one in the nodal line direction, and one in the tangential direction.

The code SMAIN4 generates a SINDA heat transfer model of a radial inflow turbine with internally cooled blades. The program obtains the geometric data of the model from the program RITTCN. 

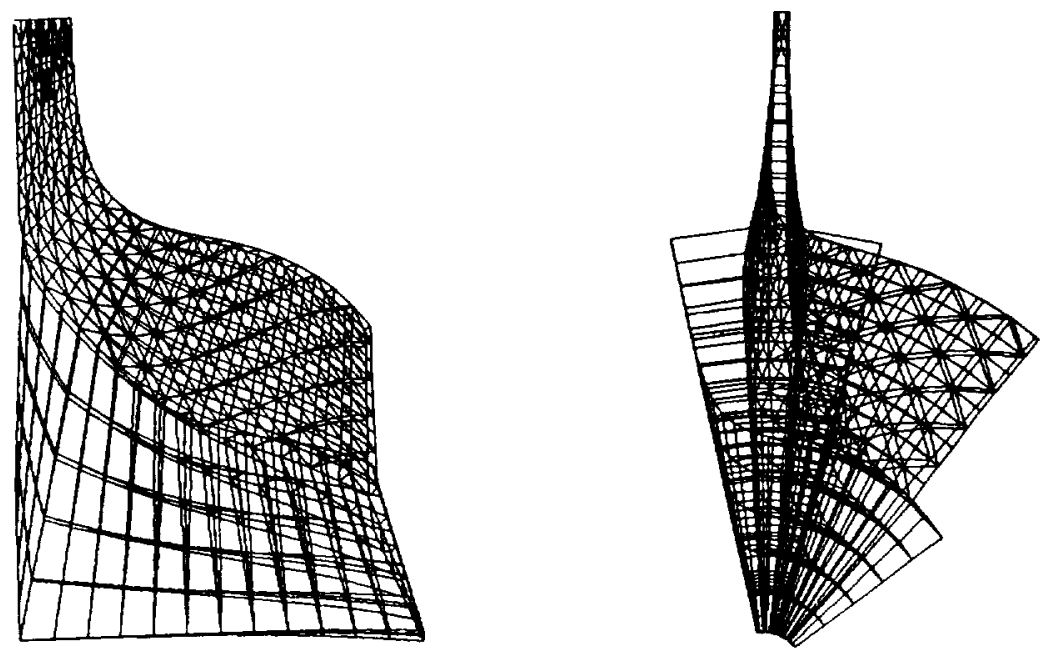

Figure 1: NASTRAN Model Generated by RITION.

A SINDA node is generated for each NASTRAN grid point within the blade. Adjacent to these, SINDA nodes are generated at the metal surfaces and at the points that represent the temperature boundary. Conductors are generated which represent the metal conduction along streamlines, along nodal lines, and through the thickness. Additional conductors are generated to represent the heat transfer coefficients between the metal's surface and the boundary nodes. A typical segmeni of the blade model is shown in Figure 2. Similar nodes and conductors are generated for the blade tips, leading edge, and root edge (Figures not shown due to space limitations).

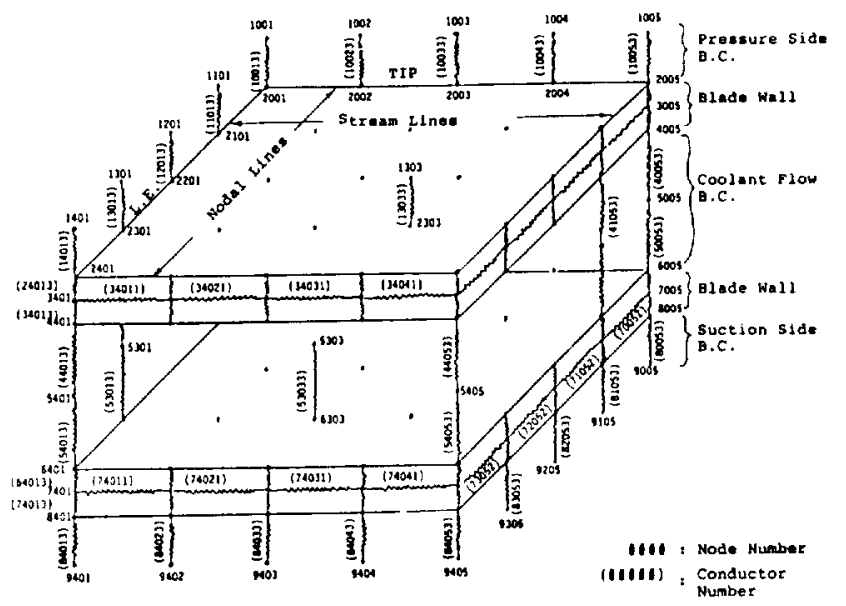

Figure 2: SINDA Blade Model.
Within the disk, a SINDA node is generated for each NASTRAN grid point. Additional nodes are generated for the temperature boundaries along the rim, back face, bore, hot gas face, and exducer end. Conductors are generated along streamlines, nodal lines, and in the tangential direction, and to represent the external heat transfer coeficients. Additional options have been incorporated which generate the thermal boundary conditions for the collant inlet channel, exit end face (exducer) and the disk's cooling passages.

\section{Boundary conditions}

The equation governing three-dimensional steady state heat conduction is of the elliptic form. Therefore, heat transfer coefficients and relative total temperature boundary conditions are required over the entire surface. The model under consideration consists of an entire blade with the corresponding disk sector. Figure 3 . shows a

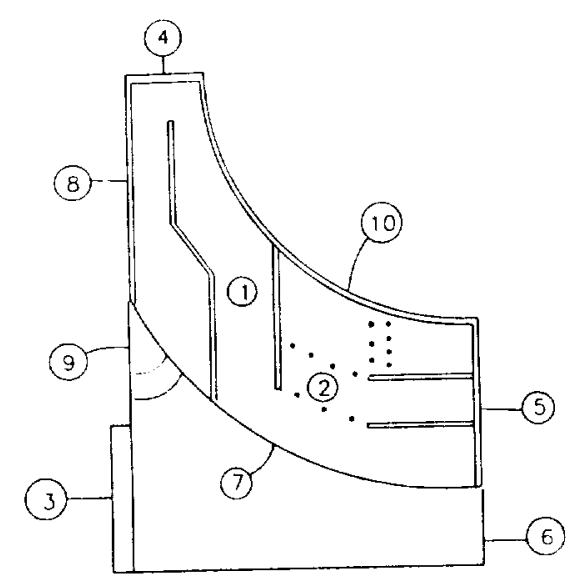

Figure 3: Rotor Boundary Oonditions and Internal Geametry. 
typical blade/disk combination. The numbers on the figure refer to the numbers of the following paragraphs.

1. Suction and Pressure External surface: The heat transfer coefficients and free stream total temperatures are obtained with the MERIDL/TSONIC/STAN5 combination.

2. Internal Cooling Passage: The heat transfer coefficients and coolant passage temperatures are computed by CPFRHA.

3. Disk Back Face: This region is connected to a shaft. A contact resistance heat transfer coefficient is used.

4. Blade Leading Edge: The heat transfer coefficients are obtained by modeling the leading edge as a cylinder in cross flow.

5. Blade Trailing Edge: The average of the suction and pressure surface heat transfer cofficients at the trailing edige are used.

6. Disk Exducer End Face: A contact resistance heat transfer coefficient is used.

7. Blade Platform: The heat transfer coefficients are taken to be the mean of the suction and pressure surface values at the blade hub. Hub platform film cooling is acoounted for by adjusting the external total temperatures.

8. Blade Scallop: Heat transfer coefficients are taken to be the average of the external suction and pressure values at the hub streamline in the scallop region.

9. Disk Rim: This is the region where the collant cames on board the rotor. The heat transfer coefficient is found by modeling the flow as an enclosed rotating disk next to a stationary wall.

10. Blade Tip: The heat transfer coefficients are the average of the suction and pressure values along the streamline.

Using the boundary conditions mentioned above, SMADN4 generates the CONDUCIOR Data and the NODE Data required as input for analysis by SINDA. The user is to supply the metal's thermal conductivity as a function of temperature in the ARRAY data as described in the SINDA user's manual. The SIV cards required to simulate baffles, pin fins, etc. are to be hand generated and added to the SINDA input deck created by SMAIN4.

The output from SINDA will be a detailed three dimensional temperature distribution in the blade and disk.

The computer program RELACT [15] then converts the output of a SINDA heat transfer analysis into the thermal Ioad imput for a NASTRAN structural analysis. REIACT has two major functions. The first is to generate the grid point temperature field cards; the second is to generate plate element field cards. The first is easily acoomplished by using relation tables that relate SINDA relative node numbers to SINDA actual node numbers, and SINDA actual nodes numbers to NASTRAN grid point numbers. Using these tables the NASTRAN grid point temperature is easily related to the SINDA relative node number which is provided by adding a few FCRIRAN statements to the SINDA analysis output calls. The above is performed for all grid points in the blade and disk. Generating the plate element field cands requires calculating the plate element's material temperature, the bottan surface temperature, the top surface temperature, an the thermal gradient through the thicloness of the element. In addition to the relation tables described above, the program requires the element connectivity and thickness data. All the relation tables and element data files are generated by either RIIION, SMANN4, or SDNDA. Very little inpurt is generated by the user. RELACT output can be directly used by PATRAN [16] for obtaining the three dimensional temperature plots (in the form of temperature bands and contour lines) onthe blade and the disk.

\section{NASTRAN Structural Analysis}

The blade and disk modeling for NASTRAN finite element analysis is created by RIIICN as explained before. The internal geometry of one blade (coolant passages) is modeled as follows:

$\begin{array}{ll}\text { Baffles } & \text { - CQUAD4 quadrilateral plate } \\ \text { Pin Fins } & \text { elements } \\ \text { Colling Ribs } & \text { - COAR rod-type elements } \\ \text { - CONR extra mass elements }\end{array}$

The pressure loads applied to the model arise from two areas:

1. Internal coolant Pressure (Data Supplied by the Code CPFRHA) Working Fluid Pressure differential across the blade (Data supplied by the MERIDL/TSONIC/STAN 5 combination).

The thermal load applied to the model is generated by the code REIACT using the output from SINDA.

A static stress and deflection analysis as well as a modal analysis can be performed on the cooled radial turbine using NASTRAN.

\section{ILUSTRATTVE APPLICATION}

A cooled radial turbine will be tested at the NASA Lewis Reasearch Center. The conditions for the test and sample application are given in Table 1. The turbine internal gecmetry is similar to that shown in Figure 3. cooling air entering the rotor gets directed to the leading edge. From there it flows down to the hub and branches into three paths exiting at the trailing edge. The flow splits indicated in the figure were abtained with a flow network analysis code which includes the mamentum equation but not the energy equation.

\section{Table 1: Turbine Input conditions}

Rotor Inlet Total Temperature Rotor Inlet Total Pressure Mass Flow Rate Speed

Total Pressure Ratio

Work coefficient $\Delta h / U^{2}$

Total Enthalpy Change

coolant Flow Rate

coolant onboard Total

Temperature

Coolant Onboand Total

Pressure
$316 \mathrm{C}$

$2.52 \mathrm{Bar}$

$2.08 \mathrm{~kg} / \mathrm{sec}$

4.05

1.0

$170 \mathrm{~kJ} / \mathrm{Kg}$

4.38 Mainflow

$-30 \mathrm{C}$

$1.58 \mathrm{Bar}$
$21570 \mathrm{rpm}$ 
Figure 4 shows the freestream critical velocity ratio distribution along the mean streamline. These are the MERIDL/TSONIC computed velocities which are used as input to STAN5. Ten streamlines between the hub and $t$ ip were chosen. The free stream velocity was "smoothed" on the suction surface of streami ines $1,2,5,6$, and 7 to eliminate separation. Figure 5 shows the location and amount of "smoothing." Generally, STAN5 predicts separation along the suction surface in regions of high diffusion. "Smoothing" the free stream velocity, or reducing the velocity gradient, will eliminate the separation. Figures 6-8 show some of the heat transfer results predicted by STAN5 for the mean streamline. STAN5 input assumptions include turbulent flow, a recovery factor of one, and a flat inlet temperature profile. Assuming a small boundary layer thickness compared to the surface's radius of curvature allows the curved blade to be modeled as a flat surface in STAN5.

The CPFRHA predicted coolant temperature and heat transfer coefficient distribution is given in Figures $9 \& 10$. High heat transfer oofficients are predicted near the tip. This leads to a cool pressure side metal temperature since the external heat transfer coefficients on this side are low. The suction side temperatures are higher due to the higher external heat transfer oofficients.

Several interlinking codes were used in the procedure to generate input files required by SMAIN4. For the above sarple application, it took only two iterations between SINDA and CPFRHA to obtain a converged temperature distribution (where the maximum change in temperature was less than 28).

PATRAN plot routines are used to display both SINIA and NASIRAN outputs. SINDA temperature distribution in the form of contours is displayed in Figure 11. The stress contours predicted by NASTRAN are shown in Figure 12 and the nodal displacements are shown in Figure 13. These figures are a representative sample of the typical graphical output generated by the above procedure.

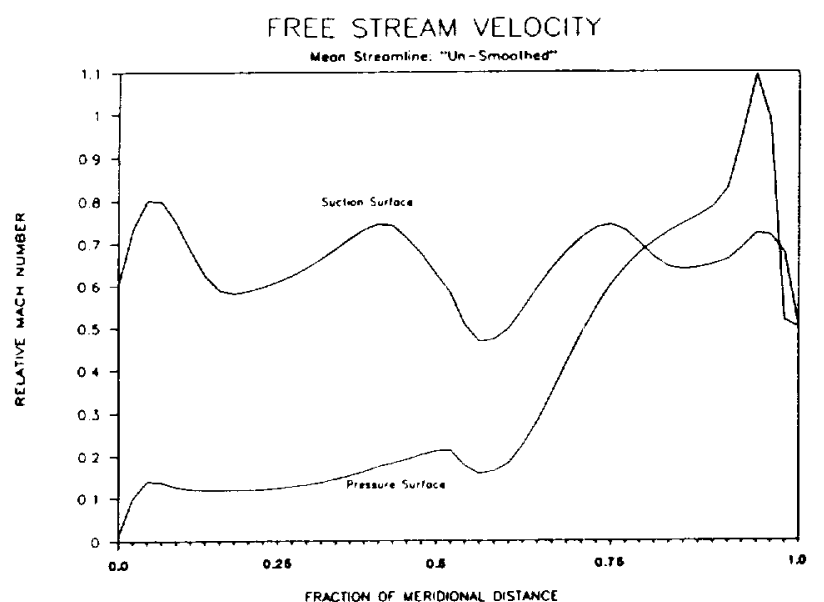

Figure 4: Blade Velocity.
FREE GTREAM VELOCITY EMOOTHEO

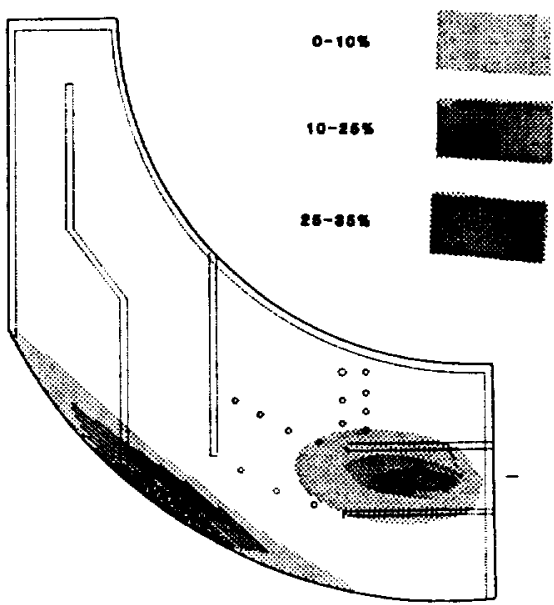

Figure 5: Freestream Velocity Smoothing.

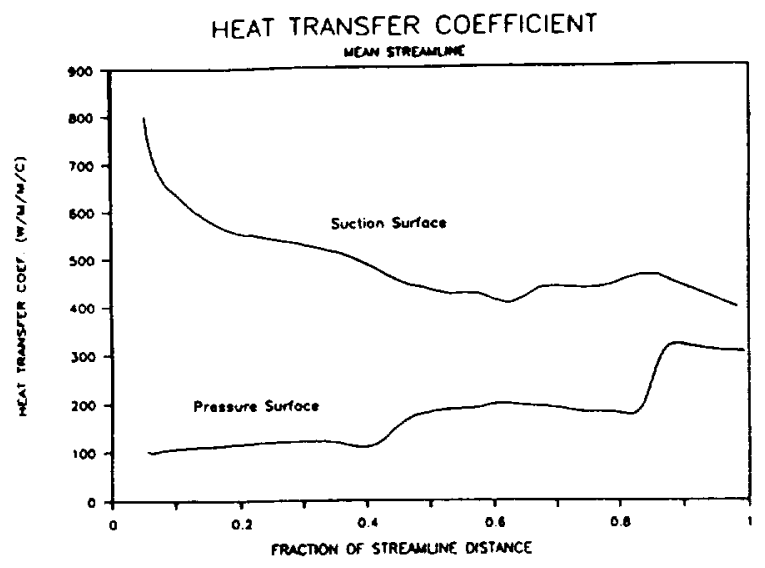

Figure 6: External leat Transfer coefficients

EXTERNAL STANTON NUMBER

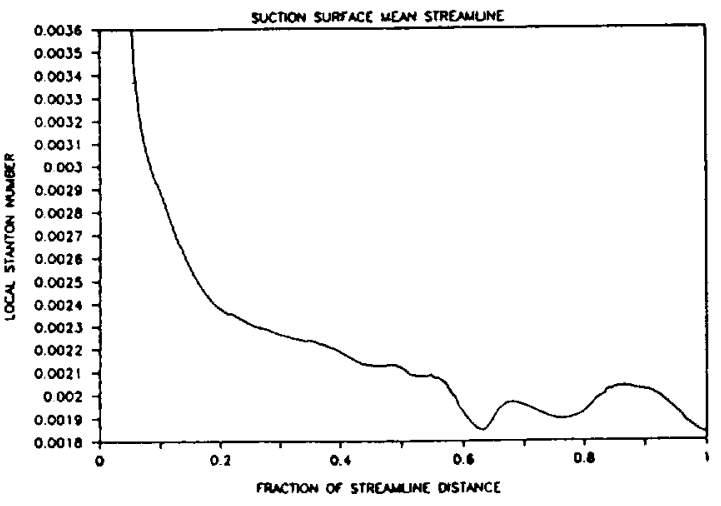

Figure 7: Stanton Muber Along Suction Surface. 


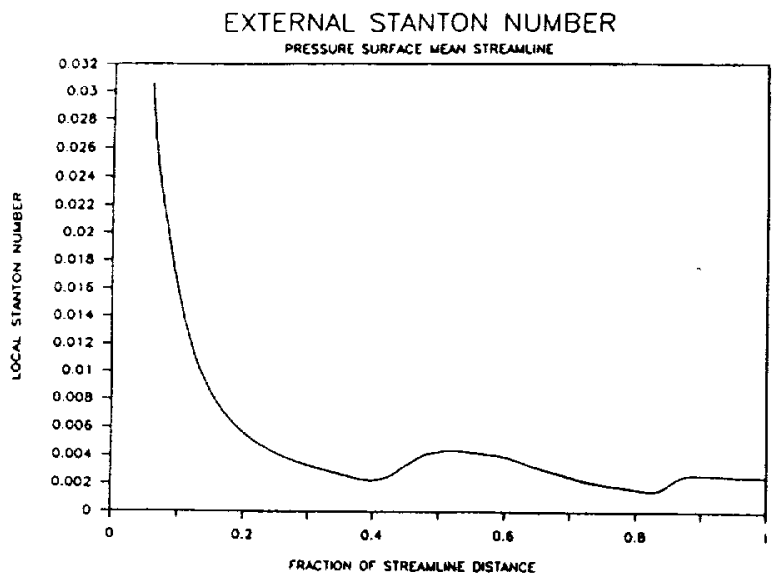

Figure 8: Stanton Number Along Pressure Surface.

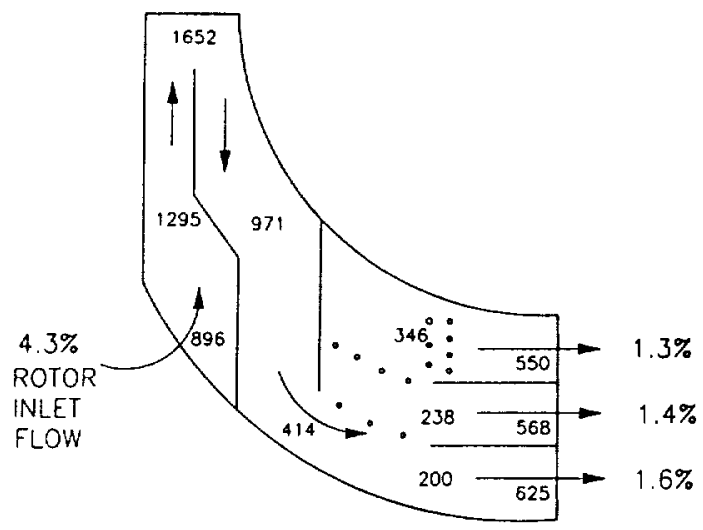

Figure 9: Internal Heat Transfer coefficients $\left(\mathrm{W} / \mathrm{M}^{2} / K\right)$.

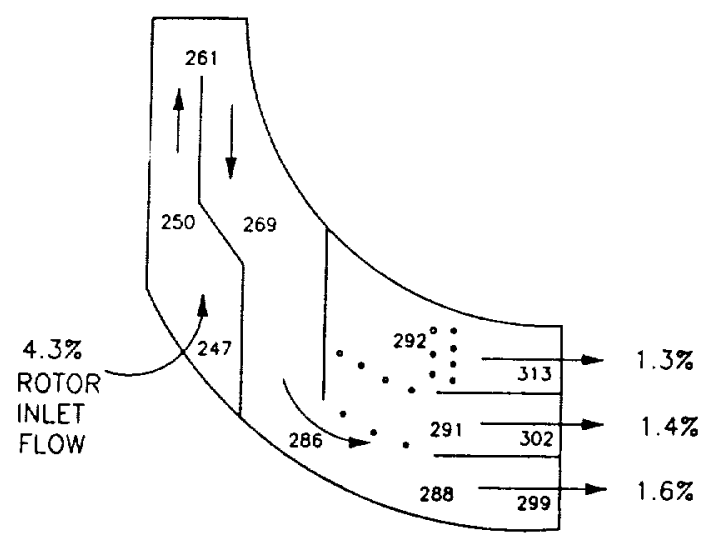

Figure 10: coolant Temperatures $({ } \mathrm{K})$.
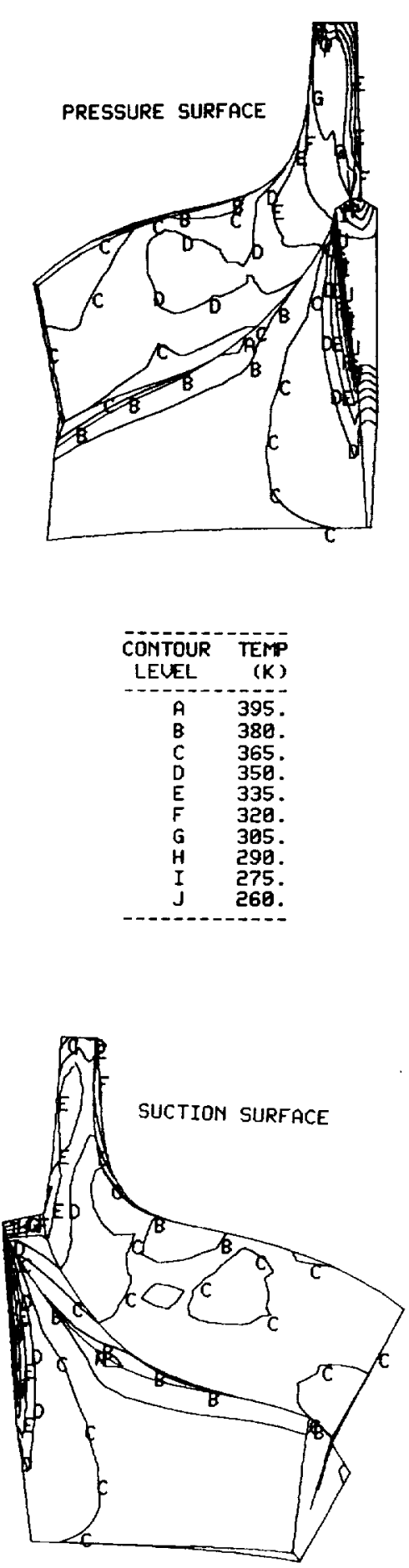

Figure 11: Temperature contours (SINDA) . 


\section{ORIGIVIS PAGE IS \\ OF POOR QUALITY}

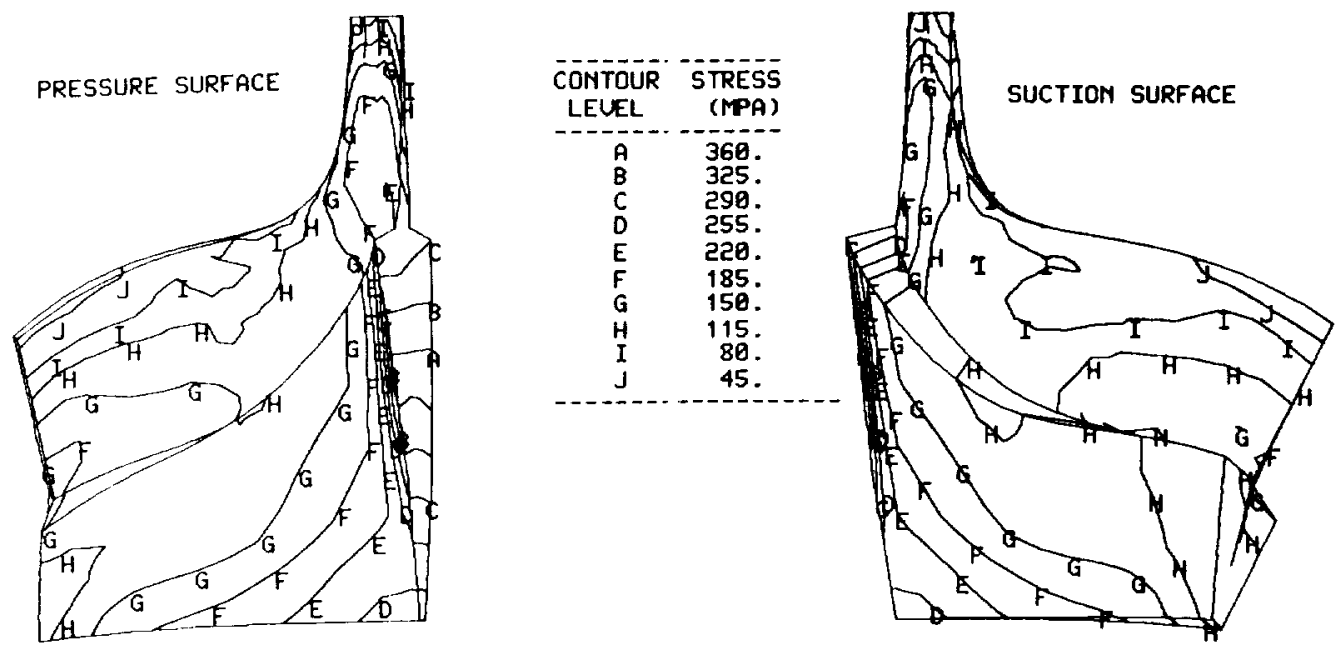

Figure 12: Stress centours (NASTRAN).

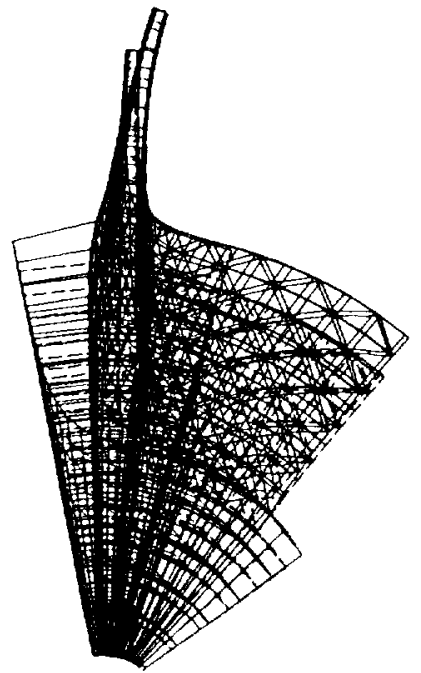

Figure 13: Nodal Displacements (NASTRAN).

Experiments leading to validation of the analysis procedure are planned for late 1988. The turbine will be tested at the conditions in Table 1. Rotor aerodynamic and heat transfer measurements are planned. Blade surface pressure, temperature and heat flux measurements will be obtained. A subsequent paper will compare the analytical and experimental results.

\section{AXIAI,RADIAL TURBINE ANALYSIS COMPARISON}

The analysis presented applies to radial turbines; although, the procedure may be extended to include axial turbines. The internal and external aerodymamic analysis to predict heat transfer coefficients and the internal coolant passage temperature prediction procedures can be applied to an axial geametry without difficulty.
The NASTRAN model generation and the NASTRAN to SINDA conversion codes must be modified before application to axial turbines.

There are several prominent differences between axial and radial turbines. The axial turbine does not have the blade scallop found in radial machines; thus, one boundary condition is eliminated. The relative total temperature alang the blade external surface is strictly a function of the radial position within the blade. A large radius change oocurs in a radial turbine as the gas passes between inlet and exit. This causes the relative total temperature to drop. This temperature change does not exist in an axial turbine since the radius change is small. The process of introducing the coolant to the blade differs between axial and radial machines. This process in an axial design may be quite similar to or different fran the radial machine under study. There are numerous other minor differenoes between the axial and radial turbine which the procedure should readily accommodate.

\section{CONCIUDING REMARKS}

An automated analysis procedure has been developed which can acomplish a rigorous thermal and structural analysis of a cooled radial aut This procedure after proper validation with the experimental data should result in a versatile analysis and design tool for cooled radial turbines.

\section{REFERENCES}

1. Rodi, w. and scheuerer, G. "Calculation of Heat Transfer to Convection Cooled Gas Turbine Blades," Transactions of the ASME, Vol. 107, July 1985, pp 620-627

2. Calvert, G. S. and Okapuu, U., "Design and Evaluation of a High Temperature Radial Turbine Phase I, "USAAVLABS Technical Report 68-69, January 1969.

3. Calvert, G. S., Beck, S. C. and Okapuu, U., "Design and Experimental Evaluation of a 
High-Temperature Radial Turbine," USAAMRDL Tectnical Report 71-20, May 1971

4. Vershure Jr., R. W., Lange, G. D., Meyer, L. J., and Lane, J. M., "A Cooled Laminated Radial Turbine Technology Demonstration," AIAA-80-0300, January 1980.

5. Ewing, D. A., Monson, D. S., and Lane, J. M., "U.S. Anmy/Detroit Diesel Allison HighTemperature Radial Turtine Demonstration," AIAA-80-0301 January 1980.

6. Katsanis, T. and McNally, พ. D., "Revised FORIRAN Program for Calculating Velocities and Streamlines on the Hub-shroud Mid channel Stream Surface of an Axial, Radial, or Mixed Flow Turbomachine or Annular Duct-I User's Manual," NASA TN D$8430,1977$.

7. Katsanis, T., "FORTRAN Program for Calculating Transonic Velocities on a Blade-to-Blade stream surface of a Turbomachine," NASA IN D-5427, 1969.

8. Crawford, M. E. and Kays, w. M. , "STAN5 - A Program for Numerical Computation of TwoDimensional Internal and External Boundary Layer Flows," NASA CR-2742, 1976.

9. Meitner, P. L., "Computer Code for Predicting coolant Flow and Heat Transfer in Turbomachinery," NASA TP. (TO be published)

10. Smith, James P.; "SINDA User's Manual" Cosmic Program MSC-18597, March 1983.

11. MSC/NASTRAN, User's Manual, MacNeal Schwendler Corporation, Los Angeles, 1984.

12. Christie, R., Tornabene, R., and Stevens, M., "Thermal' Analysis of Cooled Metal Turbine Rotor", Final Report, NASA T.O. \#856, March 1984.

13. Christie, R.T., and Stevens, M.A., "RITICNMesh Generation Program for Radical Inflow Turbines with Internal cooling for COSMIC/MSC NASTRAN", Final Report, NASA T.D. \#578.

14. Cristie, R.J., and Tornabene, R.T., "SINDA Model Generating Program for Radial Inflow Turbines with Internal Cooling", Final Report NASA T.O. \$823.

15. Crristie, R. J., "REIACT - SINDA output to NASTRAN Input Data Conversion Program for Radial Inflow Turbines with Internal Cooling", Final Report, NASA T.O. "750.

16. PATRAN Plus User Manual, PDA Engineering, 2975 Redhill Avenue, Costa Mesa, California, 92626, July 1987. 


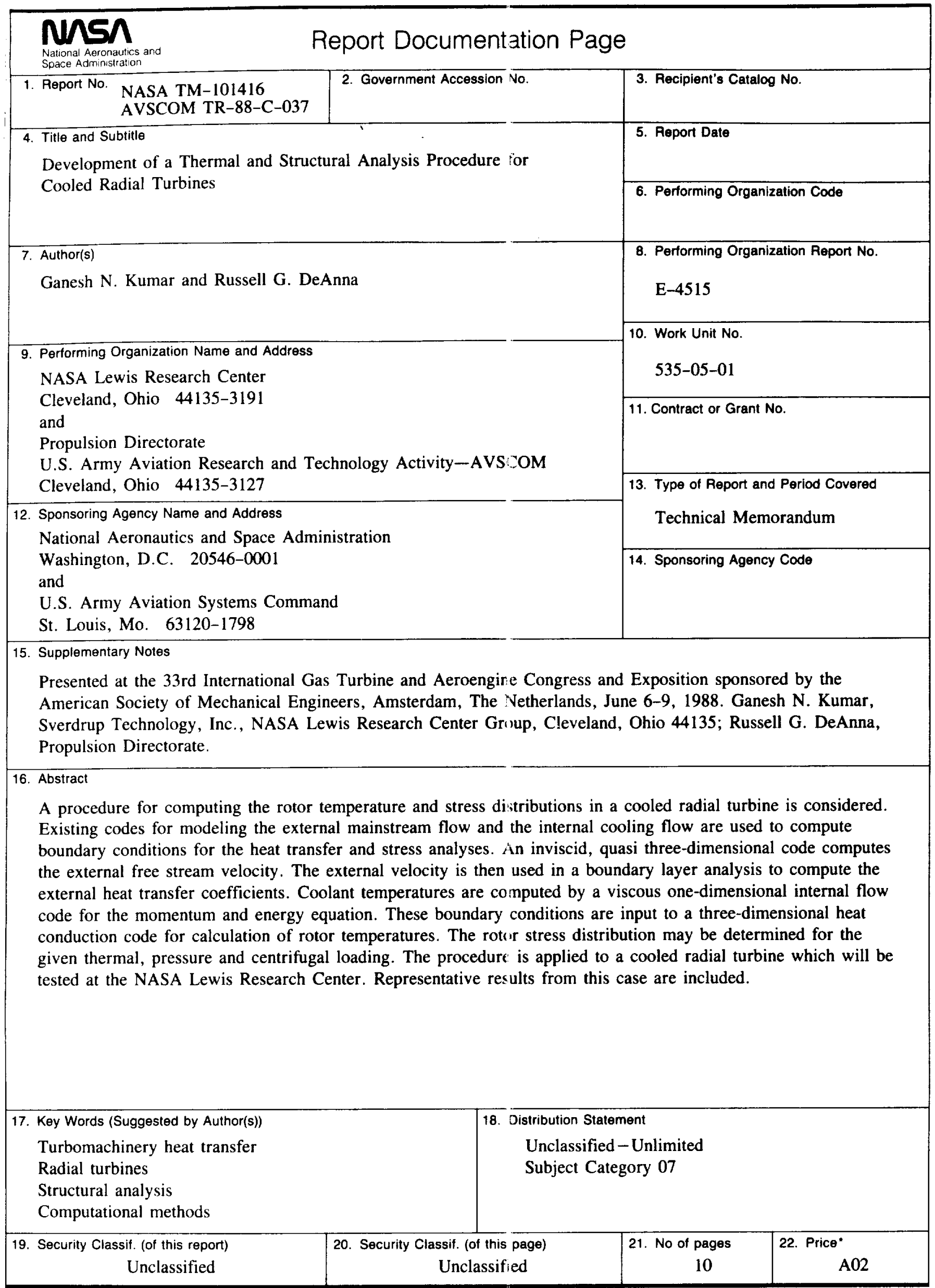


(1...

- 5 - 50 